\title{
Application of SOAP Teaching with Scenario Simulation in the General Resident Standardized Training
}

\author{
Chunxiao Liu' ${ }^{1}$, Zhiwei Zhang2*, Weiwei Ouyang ${ }^{3}$, Shangjing Liu ${ }^{4}$ \\ ${ }^{1}$ Postgraduate Management Office, The First Affiliated Hospital of Chongqing Medical University, Chongqing, China \\ ${ }^{2}$ Department of Radiology, The First Affiliated Hospital of Chongqing Medical University, Chongqing, China \\ ${ }^{3}$ Chongqing Health Service Center, Chongqing, China \\ ${ }^{4}$ Graduate School of Chongqing Medical University, Chongqing, China \\ Email: *skytxp@163.com
}

How to cite this paper: Liu, C. X., Zhang, Z. W., Ouyang, W. W., \& Liu, S. J. (2020). Application of SOAP Teaching with Scenario Simulation in the General Resident Standardized Training. Open Journal of Social Sciences, 8, 141-152.

https://doi.org/10.4236/jss.2020.87012

Received: March 27, 2020

Accepted: July 12, 2020

Published: July 15, 2020

Copyright $\odot 2020$ by author(s) and Scientific Research Publishing Inc. This work is licensed under the Creative Commons Attribution International License (CC BY 4.0).

http://creativecommons.org/licenses/by/4.0/

\begin{abstract}
Objective: To explore the effects of SOAP with scenario simulation on the clinical performance and professional identity of general residents after the standardized training. Methods: Eighty-six trainees were selected as study objects who received the general resident standardized training in Chongqing from November 2018 to October 2019, and they were divided into control group and study group using the random number table. The conventional general resident standardized training was performed in the control group, and it was conducted by combining SOAP teaching with scenario simulation in the study group. After training, the training environment acceptance and training satisfaction of trainees were evaluated using a self-designed questionnaire. And the changes in the clinical performance and professional identity of trainees were assessed by objective structured clinical examination (OSCE) and using a self-designed "general resident professional identity" questionnaire. Results: The training environment acceptance of trainees in the study group was significantly higher than that in the control group $(P<0.05)$. After training, various item scores of OSCE in both groups were evidently increased $(P<$ $0.05)$, and they were markedly greater in the study group than in the control group $(P<0.05)$; the improvement of professional identity and the training satisfaction in the study group were superior to those in the control group ( $F$ $<0.05)$. Conclusion: In the general resident standardized training, SOAP teaching with scenario simulation can effectively improve the clinical performance, training satisfaction and professional identity of general residents, thus it has good feasibility.
\end{abstract}




\section{Keywords}

Clinical Performance, General Resident, SOAP Teaching, Scenario

Simulation, Standardized Training, Professional Identity

\section{Introduction}

General medicine focuses on human-orientation, and it is a secondary professional discipline of general clinical medicine integrating the contents of several disciplines (Liu \& Jiang, 2019). For citizens, the general practitioners play a "gatekeeper" role in the health protection and the control of medical expenditures (Chi, 2018). With the industrialization, urbanization, environmental change, and accelerated aging, there is a dramatic variation in the public demand for medical services, followed by the State's new and higher requirements for general practitioners in the medical system. In accordance with the Suggestions of General Office of the State Council on Reforming and Improving the General Practitioner Cultivation and Employment Incentive Mechanism, this study was designed with the following objectives: to establish an effective hierarchical medical system, improve the primary medical service level, promote and guarantee the health services of citizens, comprehensively increase the professional attraction of general practitioners, and facilitate the transition of medical service mode; to further improve the clinical performance of general practitioners and provide a new reference for establishing a complete general resident standardized training system. In the present study, we explored the application of SOAP teaching with scenario simulation in the 2019 standardized training of general practitioners. The training results are reported below.

\section{Materials and Methods}

\subsection{General Data}

By estimating the sample size, 86 trainees were selected as study objects who received the general resident standardized training in Chongqing from November 2018 to October 2019, and they were divided into control group $(n=43)$ and study group $(n=43)$ using the random number table. In the control group, there were 22 males and 21 females (age: $22-29(24.43 \pm 3.62)$ years), 40 cases of bachelor education and 3 cases of college education; in the study group, there were 19 males and 24 females (age: 21 - 31 (24.80 \pm 3.29$)$ years), 39 cases of bachelor education and 4 cases of college education. The general data (e.g., age, sex and education) were comparable and showed no statistically significant difference between two groups $(P>0.05)$.

\subsection{General Resident Standardized Training}

The trainees in two groups all received the 12-month general resident standardized training with the training contents of "general medicine practice". The 
teacher/trainee ratio was $1 / 2$ in both groups, and the teachers with the similar age and professional title took charge of the training teaching work in a shift to make sure of no statistical difference between two groups.

\subsection{Objects and Contents of SOAP Teaching with Scenario Simulation}

In the study group, SOAP teaching with scenario simulation to improve the clinical performance was added on the basis of conventional general resident standardized training, mainly embodied by "theory training" and "general medicine clinical thinking training" modules. The contents are shown in Table 1.

\subsection{Evaluation of Training Effects}

1) Training environment acceptance of trainees: After training, the training environment acceptance of trainees was evaluated using a self-designed acceptance questionnaire based on Manchester clinical placement index (MCPI) (a medical teaching environment assessment tool) (Hyde et al., 2018; Dornan et al., 2012). The questionnaire consisted of 8 questions, including two scales of training environment (5 items) and training contents ( 3 items). Each item was scored with Likert6-level scoring standard ( 1 - 6 scores), the total score was $8-48$, and a higher score indicated the higher training environment acceptance of trainees. 2) OSCE results of trainees: Before and after training, the clinical performance of trainees was evaluated by 6-station OSCE in two days. In the first day, the total examination time was $60 \mathrm{~min}$, and the examination contents included history collection, medical record writing, general medicine clinical thinking, and clinical operation; in the second day, the total examination time was $50 \mathrm{~min}$, and the examination contents included physical examination and auxiliary examination; the total score for each station was 10.3) Assessment on the professional identity of trainees: Before and after training, all trainees completed the "general resident professional identity" questionnaire to evaluate their professional identity with the score obtained using Likert 5-level scoring standard (1 - 5 scores) (Gong, 2015; Zhao, 2010; Song, 2017; Feng et al., 2017). This questionnaire contained 10 items and involved 5 aspects of professional emotion, professional prospect recognition, professional self-efficacy, professional orientation value and professional intention (each aspect included 2 items), and a higher score indicated the higher professional identity of trainees. 4) Assessment on the self-learning effect of trainees: After training, the training effect of trainees was evaluated using a self-designed satisfaction questionnaire. This questionnaire contained 7 items (e.g., clinical thinking, clinical operation skills and doctor-patient communication skills) which were scored separately with 4 levels (3 scores, very satisfactory; 2 scores, satisfactory; 1 score, acceptable; 0 score, unsatisfactory).

\subsection{Statistical Analysis}

Excel2017 was used to save all data, and SPSS19.0 statistical software was employed for statistical analysis. The qualitative data were presented as $\mathrm{n}(\%)$, and 
Table 1. Training settings and contents of "general medicine practice" in the study group.

\begin{tabular}{|c|c|c|c|}
\hline $\begin{array}{l}\text { Preliminary } \\
\text { teaching } \\
\text { preparation }\end{array}$ & \multicolumn{3}{|c|}{$\begin{array}{l}\text { Before teaching, the teachers selected the typical clinical cases according to the requirements of the Suggestions of } \\
\text { General Office of the State Council on Reforming and Improving the General Practitioner Cultivation and } \\
\text { Employment Incentive Mechanism (GFB [2018] No. 3) and the contents \& rules of general resident standardized } \\
\text { training and by combining their clinical practice experience, special cases and problems, } \\
\text { difficulties of major diseases, and trainee problems in the previous training. }\end{array}$} \\
\hline Training mode & Training subject/contents & $\begin{array}{c}\text { Training } \\
\text { pattern }\end{array}$ & $\begin{array}{l}\text { Minir } \\
\text { case } \mathrm{n}\end{array}$ \\
\hline
\end{tabular}

1) SOAP teaching was inserted in the whole training process, its place was determined according to the condition of cases, and its purpose was to improve the general medicine clinical thinking, clinical operation skills (clinical bases and grass-root practice bases), clinical cooperation, and doctor-patient communication skills.

a) For conventional cases, the discussion was dominant in combination with teaching demonstration and practice, and it could be conducted in several forms according to the actual situations, including classroom teaching, outpatient clinic teaching, and ward teaching.

b) For typical cases, the trainees finished the history collection, physical examination, medical record writing, and treatment measure planning in a team way (4 persons/team).

2) SOAP teaching was implemented for the previously selected "typical clinical cases" in the training process.

a) The cases and the adverse outcomes caused by improper operations, knowledge shortage and incomplete case information were both analyzed using "Swiss Cheese Model" theory (Song, 2017; Feng, Wang et al., 2017).

b) Collection of subjective data ( $\mathrm{S}$ - The subjective data were collected by the patients' chief complaint and clinically asking the patients' age, disease development, current symptoms, personal history and familial history. The trainees should make clinical reasoning through thinking and integrating the information provided by the patients during clinical inquiry. The clinical inquiry was implemented under the guidance of teachers, and the trainees were allowed to propose some questions.

c) Collection of objective data (O) - The objective data (e.g., symptoms and signs) of

SOAP teaching patients were collected by systematic examination, physical diagnosis, X-ray examination, CT, ECG, biochemical test and other auxiliary examination under the guidance of teachers, and the trainees were allowed to participate in the discussion about the interpretation of auxiliary examination results.

d) Patient assessment (A) - The analysis, differential diagnosis and prognosis evaluation were performed according to the abovementioned subjective and objective data under the guidance of teachers; the teachers properly put forward to some relevant questions and the trainees participated in the discussion.

e) Treatment plan $(\mathrm{P})-\mathrm{A}$ comprehensive treatment plan was made for cases by combining the above three steps of $\mathrm{S}, \mathrm{O}$ and $\mathrm{A}$ under the guidance of teachers. The teachers proposed some special questions for the cases, and the trainees worked out the treatment plans and wrote the medical records.

f) The teachers assessed the cases analyzed independently by trainees and then the trainees with qualified performance entered into the scenario simulation step.

3) Scenario simulation

a) For 2 cases discussed previously, 4 trainees simulated the patients in turn, the remaining trainees participated in the treatment, and the teachers controlled the scenario simulation workflow and time to make sure that all trainees joined in such scenario simulation and required the trainees to work out the treatment measures within the specified time.

b) After all trainees completed the scenario simulation, the teachers provided a summary assessment according to the scenario simulation, treatment measures, doctor-patient communication and clinical cooperation of trainees.
Case discussion, case review, case simulation 2 cases/times (1 times/week)

Note: In the case discussion or case review process, the teacher/trainee ratio was $2 / 1$, i.e., the teachers gave a classroom lecture by SOAP teaching for $1 / 2$ case and put forward to some questions to be answered by trainees; the trainees independently analyzed $1 / 2$ case, and then the teachers assessed, supplemented and corrected the analysis results.

2 scenarios/week 
the quantitative data were expressed as $\bar{x} \pm s$. All data were compared with $t$ test, and $P<0.05$ suggested a statistically significant difference.

\section{Results}

\subsection{Analysis of Questionnaire Reliability}

As shown by the internal consistency test (Table 2), Cronbach's a coefficient of trainee's training environment recognition questionnaire, trainee's professional identity questionnaire and trainee's self-learning effect satisfaction questionnaire was $0.715,0.833$ and 0.849 , respectively. Based on the previous studies, it indicates good consistency among questionnaire items if Cronbach's a coefficient is $>0.7$. Therefore, three questionnaires in this study had good internal reliability, as well as high evaluation stability and reliability.

\subsection{Training Environment Acceptance of Trainees (Score)}

As shown by the scoring of training environment and training contents in two groups, the training environment acceptance score in the study group was better than that in the control group, and there was a statistically significant difference between two groups $(P<0.05)$ (Table 3$)$.

\subsection{Evaluation on the Clinical Performance of Trainees}

Before training, OSCE of trainees in two groups was completed, involving history collection, medical record writing, general medicine clinical thinking, clinical operations, physical examination and auxiliary examination analysis. The OSCE results showed no statistically significant difference between two groups $(P<$ 0.05). In both groups, various item scores of OSCE were significantly increased

Table 2. Internal consistency of questionnaires.

\begin{tabular}{ccc}
\hline Questionnaire & Cronbach's a & Number of items \\
\hline Trainee's training environment recognition questionnaire & 0.715 & 8 \\
Trainee's professional identity questionnaire & 0.833 & 10 \\
Trainee's self-learning effect satisfaction questionnaire & 0.849 & 7 \\
\hline
\end{tabular}

Table 3. Comparison of training environment acceptance score between two groups.

\begin{tabular}{cccc}
\hline Group & Training environment & Training contents & Total score \\
\hline Control group $(\mathrm{n}=43)$ & $22.37 \pm 1.96$ & $12.28 \pm 2.15$ & $35.19 \pm 2.16$ \\
Study group $(\mathrm{n}=43)$ & $23.63 \pm 2.04$ & $15.17 \pm 1.39$ & $40.58 \pm 2.25$ \\
$t$ value & -2.921 & -7.402 & -11.332 \\
$P$ value & 0.005 & $<0.001$ & $<0.001$ \\
\hline
\end{tabular}


after training $(P<0.05)$. After training, the OSCE scores of trainees (history collection, medical record writing, general medicine clinical thinking, clinical operations, physical examination and auxiliary examination analysis) were markedly greater in the study group than in the control group, and there was a statistically significant difference between two groups $(P<0.05)$ (Table 4$)$.

\subsection{Comparison of OSCE Results between Males and Females}

After training, the OSCE results in the study group were compared between males and females using independent sample $t$ test. The results showed that in the history collection, general medicine clinical thinking, clinical operations, physical examination, and auxiliary examination analysis, there was no statistically significant difference between males and females $(P>0.05)$; the medical record writing score of females was significantly higher than that of males $(P<0.05)$ (Table 5).

\subsection{Professional Identity of Trainees before and after Training}

Before training, there was no statistically significant difference in various item scores of "general resident professional identity" questionnaire between two groups $(P>0.05)$. After training, there was an increase in the scores of professional emotion, professional prospect recognition, professional self-efficacy, professional orientation value and professional intention in two groups, and the scores of trainee's professional identity questionnaire were significantly higher in the study group than in the control group $(P<0.05)$ (Table 6).

\subsection{Comparison of Professional Identity between Males and Females}

After training, the professional identity in the study group was compared between males and females using independent sample $t$ test. The results showed that in the scores of professional emotion, professional prospect recognition,

Table 4. Comparison of OSCE results in two groups before and after training.

\begin{tabular}{|c|c|c|c|c|c|c|c|c|}
\hline \multirow[b]{2}{*}{ Item } & \multicolumn{4}{|c|}{ Before training } & \multicolumn{4}{|c|}{ After training } \\
\hline & $\begin{array}{l}\text { Control group } \\
\qquad(\mathrm{n}=43)\end{array}$ & $\begin{array}{l}\text { Study group } \\
\qquad(\mathrm{n}=43)\end{array}$ & $t$ value & $P$ value & $\begin{array}{l}\text { Control group } \\
\qquad(\mathrm{n}=43)\end{array}$ & $\begin{array}{l}\text { Study group } \\
\qquad(\mathrm{n}=43)\end{array}$ & $t$ value & $P$ value \\
\hline History collection & $6.13 \pm 1.27$ & $6.08 \pm 1.33$ & 0.178 & 0.859 & $7.09 \pm 1.35^{\star}$ & $7.95 \pm 1.62^{\text {立 }}$ & -2.674 & 0.01 \\
\hline Medical record writing & $5.76 \pm 1.08$ & $5.81 \pm 1.04$ & -0.219 & 0.827 & $6.53 \pm 1.19^{\star}$ & $7.06 \pm 1.12^{\text {占 }}$ & -2.127 & 0.036 \\
\hline General medicine clinical thinking & $5.48 \pm 1.47$ & $5.44 \pm 1.49$ & 0.125 & 0.901 & $6.67 \pm 1.51^{\star}$ & $7.55 \pm 1.62^{\text {占 }}$ & -2.606 & 0.011 \\
\hline Clinical operations & $5.79 \pm 1.35$ & $5.73 \pm 1.38$ & 0.204 & 0.839 & $7.24 \pm 1.05^{\star}$ & $7.99 \pm 1.27^{\text {光 }}$ & -2.985 & 0.004 \\
\hline Physical examination & $6.25 \pm 1.46$ & $6.30 \pm 1.42$ & -0.161 & 0.873 & $7.18 \pm 1.64^{\star}$ & $8.04 \pm 1.59^{\text {मे }}$ & -2.467 & 0.016 \\
\hline Auxiliary examination analysis & $5.43 \pm 1.36$ & $5.39 \pm 1.40$ & 0.134 & 0.893 & $6.71 \pm 1.50^{\star}$ & $7.38 \pm 1.46^{\text {出 }}$ & -2.099 & 0.039 \\
\hline
\end{tabular}

Note: Intra-group comparison before the same training, ${ }^{\star \text { 㧒 }} P<0.05$. 
professional self-efficacy, professional orientation value and professional intention, there was no statistically significant difference between males and females $(P>0.05)$ (Table 7).

\subsection{Comparison of Trainee's Self-Learning Effect between Males and Females}

After training, the trainee's self-learning effect in the study group was compared between males and females using independent sample $t$ test (Table 8). The results showed that in the scores of trainee's self-learning effect ( 7 items), there was no statistically significant difference between males and females $(P>0.05)$.

\section{Discussion}

The establishment and development of general practitioner system in different countries is closely associated with the national medical system, the economic and social development, the government system and the public health demand. After the development of several decades, a complete general practitioner system has been established successively in many countries (Wang et al., 2018; Zhou, 2019; Zhang et al., 2018). However, there is the relatively late development of

Table 5. Comparison of OSCE results in the study group after training between males and females.

\begin{tabular}{ccccc}
\hline & Males $(\mathrm{n}=19)$ & Females $(\mathrm{n}=24)$ & $t$ value & $P$ value \\
\hline History collection & $7.93 \pm 1.59$ & $7.96 \pm 1.60$ & -0.061 & 0.951 \\
Medical record writing & $6.58 \pm 1.15$ & $7.39 \pm 1.08$ & -2.373 & 0.022 \\
General medicine clinical thinking & $7.69 \pm 1.70$ & $7.47 \pm 1.75$ & 0.415 & 0.681 \\
Clinical operations & $8.13 \pm 1.30$ & $7.76 \pm 1.14$ & 0.993 & 0.326 \\
Physical examination & $7.52 \pm 1.43$ & $8.14 \pm 1.62$ & -1.312 & 0.197 \\
Auxiliary examination analysis & $7.32 \pm 1.50$ & $7.41 \pm 1.49$ & -0.196 & 0.845 \\
\hline
\end{tabular}

Table 6. Comparison of "general resident professional identity" questionnaire scores in two groups before and after training.

\begin{tabular}{|c|c|c|c|c|c|c|c|c|}
\hline \multirow[b]{2}{*}{ Item } & \multicolumn{4}{|c|}{ Before training } & \multicolumn{4}{|c|}{ After training } \\
\hline & $\begin{array}{l}\text { Control group } \\
\qquad(\mathrm{n}=43)\end{array}$ & $\begin{array}{l}\text { Study group } \\
\quad(\mathrm{n}=43)\end{array}$ & $t$ value & $P$ value & $\begin{array}{l}\text { Control group } \\
\qquad(\mathrm{n}=43)\end{array}$ & $\begin{array}{l}\text { Study group } \\
\quad(\mathrm{n}=43)\end{array}$ & $t$ value & $P$ value \\
\hline Professional emotion & $4.69 \pm 1.38$ & $4.63 \pm 1.42$ & 0.199 & 0.843 & $5.51 \pm 1.76^{\star}$ & $6.93 \pm 1.84^{\text {th }}$ & -3.657 & $<0.001$ \\
\hline Professional self-efficacy & $4.84 \pm 1.69$ & $4.73 \pm 1.75$ & 0.297 & 0.768 & $5.82 \pm 1.66^{\star}$ & $7.06 \pm 1.53^{\text {尔 }}$ & -3.602 & 0.001 \\
\hline Professional orientation value & $4.19 \pm 1.73$ & $4.24 \pm 1.62$ & -0.138 & 0.890 & $5.62 \pm 1.58^{\star}$ & $6.73 \pm 1.68^{\text {质 }}$ & -3.156 & 0.002 \\
\hline Professional intention & $4.05 \pm 1.25$ & $4.13 \pm 1.17$ & -0.306 & 0.760 & $5.37 \pm 1.41^{\star}$ & $6.72 \pm 1.57^{\text {年 }}$ & -4.195 & $<0.001$ \\
\hline
\end{tabular}

Note: Intra-group comparison before the same training, ${ }^{\star}$ 约 $P<0.05$. 
Table 7. Comparison of the scores of "general resident professional identity" questionnaire in the study group after training between males and females.

\begin{tabular}{ccccc}
\hline & Males $(\mathrm{n}=19)$ & Females $(\mathrm{n}=24)$ & $\mathrm{t}$ value & P value \\
\hline Professional emotion & $6.85 \pm 1.87$ & $6.95 \pm 1.83$ & 0.176 & 0.861 \\
Professional prospect recognition & $6.59 \pm 1.48$ & $6.55 \pm 1.52$ & 0.086 & 0.931 \\
$\begin{array}{c}\text { Professional self-efficacy } \\
\text { Professional orientation value }\end{array}$ & $6.03 \pm 1.56$ & $7.09 \pm 1.52$ & -0.127 & 0.899 \\
Professional intention & $6.73 \pm 1.62$ & $6.71 \pm 1.69$ & 0.078 & 0.938 \\
\hline
\end{tabular}

Table 8. Comparison of the trainee's self-learning effect in the study group after training between males and females.

\begin{tabular}{ccccc}
\hline Evaluation item & $\begin{array}{c}\text { Control group } \\
(\mathrm{n}=43)\end{array}$ & $\begin{array}{c}\text { Study group } \\
(\mathrm{n}=43)\end{array}$ & t value & P value \\
\hline $\begin{array}{c}\text { Effective improvement of } \\
\text { clinical thinking }\end{array}$ & $1.49 \pm 0.53$ & $2.69 \pm 0.84$ & -7.923 & $<0.001$ \\
$\begin{array}{c}\text { Effective improvement of } \\
\text { clinical operation skills }\end{array}$ & $1.95 \pm 0.42$ & $2.27 \pm 0.53$ & -3.103 & 0.003 \\
$\begin{array}{c}\text { Effective improvement of } \\
\text { doctor-patient communication skills }\end{array}$ & $1.52 \pm 0.36$ & $2.34 \pm 0.54$ & -8.285 & $<0.001$ \\
$\begin{array}{c}\text { Effective improvement of clinical } \\
\text { risk management capability }\end{array}$ & $1.37 \pm 0.29$ & $2.21 \pm 0.63$ & -7.942 & $<0.001$ \\
$\begin{array}{c}\text { Effective improvement of } \\
\text { clinical cooperation }\end{array}$ & $1.65 \pm 0.37$ & $2.20 \pm 0.58$ & -5.242 & $<0.001$ \\
$\begin{array}{c}\text { Effective improvement of } \\
\text { patient-centered service awareness }\end{array}$ & $1.53 \pm 0.41$ & $2.26 \pm 0.37$ & -8.668 & $<0.001$ \\
$\begin{array}{c}\text { Effective improvement of } \\
\text { problem analysis and solution }\end{array}$ & $1.69 \pm 0.58$ & $2.38 \pm 0.51$ & -5.858 & $<0.001$ \\
\hline
\end{tabular}

general medicine in China. General practitioners play a very important role in the primary medical service after the introduction of general medicine concept to China, the proposal of the policy of "accelerate the development of general medicine and cultivate general practitioners", the implementation of general practitioner training pilot program, and the all-around top-down design of general practitioner system under the socialism with Chinese characteristics. In the current medical system, there are many issues concerning the number, comprehensive quality, professional identity and cultivation system of general practitioners (Wu et al., 2018). To cultivate the high-quality general practitioners and strengthen the construction of the national medical team, the general resident standardized training becomes a critical key in the new medical reform. 
Most studies of general resident training practice in the recent years focus on the clinical thinking (Yang et al., 2018b), some certain aspect (Zhao \& Gao, 2019), or the system and current situation of general resident standardized training system (Zhang et al., 2017; Tian et al., 2017), but there are few studies about the effects of training settings on the comprehensive clinical skills of trainees, e.g., operation skills, communication skills, clinical thinking, and risk management. In this study, combining the status quo and existing issues of general practitioner training in China (Wu et al., 2018) and the limitations of general practitioners in the clinical operation and cooperation during practice, and according to the requirements of the Suggestions of General Office of the State Council on Reforming and Improving the General Practitioner Cultivation and Employment Incentive Mechanism (GFB [2018] No. 3), we explored the application of SOAP teaching with scenario simulation in the general resident standardized training.

\subsection{Significance of SOAP Teaching for General Practitioners}

SOAP is the internationally most common question-orientated medical record approach, and it supports systematically and simply recording the subjective/ objective data and treatment plans of patients and effectively developing the treatment and management measures of patients, facilitates the communication of medical staffs, provides the reasonable and necessary evidences, and helps the improvement of medical quality control (Alexandre et al., 2019). It has been proven that SOAP teaching has the application advantages in the rehabilitation teaching field (Zhao et al., 2019). SOAP medical record is a structured primary care medical record proposed in the International Classification of Primary Care (ICPC) system (World Organization of National Colleges, Academies and Academic Associations of General Practitioners/Family Physicians (WONCA)) to organize and record the diagnosis and treatment activities of general medicine (Yan et al., 2017). During general medical diagnosis and treatment, the general practitioners (mostly providing services in the gross-root medical institutions) need to handle not only the conventional physiological issues, but also many aspects concerning the healthy issues of patients, such as family, society, and mentality; and they often treat the patients without apparent symptoms and thus difficultly make a definite diagnosis in a short time. There is a difficulty in collecting the patient information in a form of conventional medical record. SOAP is question-orientated and can more comprehensively reflect the physiological, psychological, behavioral and social conditions of patients and the progression of undifferentiated diseases and chronic diseases. In other words, the clinical performance of general practitioners is evaluated by analyzing the quality of SOAP writing during the training examination. Therefore, SOAP teaching was introduced to the general resident standardized training in this study.

\subsection{Effects of SOAP Teaching on General Practitioners}

Compared with the conventional general resident standardized training, SOAP 
teaching with scenario simulation greatly improved the training environment acceptance of trainees, led to more significant improvement of objective training satisfaction and OSCE results reflecting the clinical performance of general residents, and demonstrated more ideal results of professional identity. In this study, the training with SOAP teaching for improving the clinical performance was conducted to systematically teach the basic theories and cultivate the general medicine clinical thinking, so that the trainees deeply mastered the theoretical knowledge of general medicine and effectively improved their self-thinking, clinical reasoning and clinical operation skills from the theoretical knowledge and clinical practice to the general medicine clinical thinking. Besides, the combination of theories and practice reinforced the comprehension of trainees to the disease diagnosis \& treatment, disease prevention and health management, and enhanced their sense of mission to take the responsibilities; as a result, the trainees had more profound recognition to general medicine and stronger professional identity. Furthermore, the scenario simulation widely applied in the fields of cardiology and pediatrics (Zou \& Luo, 2017; Sarah et al., 2018) was adopted so that the trainees could comprehensively know the feelings, demands, symptoms and disease onset of patients during the diagnosis and treatment of the simulated cases; it well embodies the training concept of "pay importance to trainee participation" and facilitates the cultivation of trainees in aspect of team cooperation, doctor-patient communication, problem analysis and solution, and service awareness.

In our study, SOAP teaching was combined with the scenario simulation, i.e., the risk factors of crisis events were analyzed using "Swiss Cheese Model" theory to improve the clinical risk management capability of general residents. As the medical safety in the clinical practice is greatly associated with the mistakes of medical staffs, that is to say, such mistakes are one of important causes for adverse consequences (e.g., disease deterioration and medical damage), the risk management capability is an indispensable part of clinical performance. It is coincident to the expectation that the trainees in this study thought SOAP teaching was beneficial for improving the clinical risk management capability.

At present, with the popularization of hierarchical medical system and the proposal of "Healthy China" strategy, the general practitioners play a very important role in the public primary medical services. SOAP teaching with scenario simulation can effective improve the professional identity and clinical performance of general residents, and it is of great significance for the cultivation of general medical talents.

\subsection{Study Shortcomings and Prospect}

The comprehensive clinical skills and professional identity of general practitioners are the key for their stable development, while the complete general practitioner standardized training system is the foundation to cultivate the excellent general practitioners (Zheng et al., 2019). At present, the domestic gener- 
al practitioner team still needs expanding continuously to meet the primary care demand, and the professional identity, comprehensive clinical skills and satisfaction of general practitioners are required to be improved and promoted ceaselessly (Yang et al., 2018a). In this study, we only explored the effects of SOAP teaching with scenario simulation on the skills, professional identity and satisfaction of general practitioners. The investigation from a view of incentive mechanism, cultivation system (staffing, professional title evaluation, and work assessment) and professional attraction (salary, employment management measures, and professional development prospect) is needed to build up a complete general practitioner team adaptive to the industrial requirements, enhance the primary medical service, and radically address the public issues of "difficult access to medical care" and "expensive medical care".

\section{Fund}

2018 Medical Research Projects of Chongqing Health Commission \& Chongqing Science and Technology Bureau: Study on the clinical performance and evaluation of general residents after standardized training and the relevant strategies (2018MSXM135); National Medical Professional Degree Graduate Education Steering Committee Project (B2-YX20180202-10): Construction and practice of the Scientific Research Capability Cultivation System of Clinical Medicine Master Professional Degree Graduate.

\section{Conflicts of Interest}

The authors declare no conflicts of interest regarding the publication of this paper.

\section{References}

Alexandre, C., Joyce, Y.-C. L. et al. (2019). Perception of Electronic Peer Review of SOAP Notes among Pharmacy Students Enrolling in Their First Pharmacotherapeutics Course. Currents in Pharmacy Teaching and Learning, 11, 1259-1264. https://doi.org/10.1016/j.cptl.2019.09.005

Chi, C. H. (2018). Construction of "Health China 2030" and the General Practitioner Team. The Science of Leadership Forum, 134, 78-98.

Dornan, T., Muijtjens, A., Graham, J. et al. (2012). Manchester Clinical Placement Index (MCPI). Conditions for Medical Students' Learning in Hospital and Community Placements. Advances in Health Sciences Education, 17, 703-716. https://doi.org/10.1007/s10459-011-9344-x

Feng, W., Wang, X. H., Qian, Y. et al. (2017). Development and Empirical Analysis of Professional Identity Scale for Community Doctors. Soft Science of Health, 31, 47-52.

Gong, K. Y. (2015). Study on the Current Situation and Influential Factors of Professional Self-Identity of Medical Social Workers.

Hyde, S., Hannigan, A., Dornan, T. et al. (2018). Medical School Clinical PlacementsThe Optimal Method for Assessing the Clinical Educational Environment from a Graduate Entry Perspective. BMC Medical Education, 18, 7-14.

https://doi.org/10.1186/s12909-017-1113-y 
Liu, X. X., \& Jiang, J. H. (2019). Exploration on the Future Development and Trend of General Medicine in the Tertiary Hospitals. Cardiovascular Disease Journal of Integrated Traditional Chinese and Western Medicine (Electronic), 7, 14-15.

Sarah, C., Lisa, E., \& Sarah, D. (2018). The Impact of Simulation Based Education on Nursing Confidence, Knowledge and Patient Outcomes on General Medicine Units. Nurse Educator in Practice, 29, 70-75. https://doi.org/10.1016/j.nepr.2017.11.017

Song, Y. P. (2017). Career Cognition and Career Intention among General Practitioners in China: The Mediating Effect of Income Expectation and Career Identity. Chinese Journal of Health Policy, 10, 77-82.

Tian, B., Jiang, R. S., Zhou, M. et al. (2017). A Survey on the Evaluation of the CURRENT Base Teaching Management from General Resident Standardized Trainees in Yunnan. Medical Education Research and Practice, 25, 96-98.

Wang, Q. Y., Min, R., Su, M. et al. (2018). Enlightenment from the Operation Modes of General Practitioners in the UK and USA. Journal of Public Health and Preventive Medicine, 29, 83-86.

Wu, H. Y., Ding, R., Zhang, W. et al. (2018). Exploration and Practice of Clinical Medicine (General Medicine) Master Degree Education + Resident Standardized Training in the Local Medical Colleges. Anhui Medical and Pharmaceutical Journal, 22, 207-210.

Yan, L. L., Chao, C., \& Guang, H. J. (2017). Reasons for Encounter and Health Problems Managed by General Practitioners in the Rural Areas of Beijing, China: A Cross-Sectional Study. PLoS ONE, 12, e0190036. https://doi.org/10.1371/journal.pone.0190036

Yang, H. M., Yin, D. L., Xin, Q. Q. et al. (2018a). Current Status of Continuing Medical Education for Primary General Practitioners in China. Chinese Journal of General Practice, 16, 1375-1378.

Yang, X. L., He, H. W., Lu, X. et al. (2018b). Preliminary Application of Problem-Based Learning Combined Case-Based Learning Teaching Methods in Standardized Training of General Practitioners. Chinese Journal of Medical Education, 38, 722-725.

Zhang, L. P., Ma, X. J., \& Xia, Q. S. (2018). Overseas General Practitioner Cultivation Modes and Their Enlightenments. Shanxi Medical Journal, 47, 52-54.

Zhao, H. (2010). Testing for Reliability and Validity of Chinese Version of the Nurse's Career Identity Scale. Chinese Nursing Management, 10, 49-51.

Zhao, T., \& Gao, P. (2019). Use of the Whole Course Management in Ophthalmology Standardized Training of General Practitioners. Chinese Journal of Medical Education, 39, 375-378.

Zhao, Y. J., Liu, R. F., Huang, G. Z. et al. (2019). Application of SOAP Assessment Note-Based Case Discussion Teaching Pattern in the Clinical Practice Teaching of Rehabilitation. Chinese Journal of Rehabilitation Medicine, 34, 80-82.

Zhang, D. Q., Liu, Y., He, P. et al. (2017). Survey on Status Quo of 5 Standardized Training Bases of Our Country " $5+3$ " General Practitioners. Chongqing Medicine, 46, 3950-3952.

Zheng, J. T., Fang, J., Dong, A. M. et al. (2019). Introspection and Suggestions of Teaching and Assessment Patterns in the Standardized Training of General Residents. Chinese Journal of General Practitioners, 18, 694-696.

Zhou, W. (2019). The Enlightenment and Thinking of the British General Practice System on the Work of General Practice in China. Zhejiang Medical Education, 18, 16-18.

Zou, Z., \& Luo, R. (2017). Application of Scenario Simulation-Based Clinical Workshops in the Cardiology Teaching. Chongqing Medicine, 46, 4882-4885. 